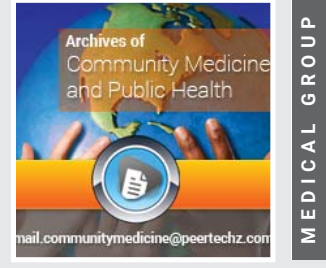

Opinion

\section{Outbreak of Respiratory Tract Infection Score (ORTIS): Objective Screening for Children to Rule Out COVID-19 and Prevent Nosocomial}

\section{Spread}

\author{
Varnit Shanker* \\ Consultant, Pediatrics and Neonatology, University: Harvard University (HES), D-196 Jagdish Marg \\ Bani Park, Jaipur, 302016, India
}

Received: 11 April, 2020

Accepted: 20 April, 2020

Published: 21 April, 2020

*Corresponding author: Varnit Shanker, Consultant, Pediatrics and Neonatology, University: Harvard University (HES), D-196 Jagdish Marg Bani Park, Jaipur, 302016, India, Tel: +91 9929779306;

E-mail:vas500@g.harvard.edu

https://www.peertechz.com

Check for updates
Since December 2019, over two million people worldwide have been affected by coronavirus disease 2019 (COVID-19). Because of quarantine measures, overcrowded healthcare facilities, fear of contracting the disease and forced behavioural modification to suspect every respiratory tract infection as a potential COVID-19 case - parents of sick children are hesitant to contact healthcare facilities in developing countries such as India. Acute shortage of specialist care has led to increased suffering of children affected by other diseases. Such patients are being continuously received in critical state due to a delay in contact. In resource scarce settings with an incomplete understanding of the disease process, there is also a lack of confidence amongst pediatricians while screening the patients for COVID-19 clinically. This problem has compounded due to infected doctors and staff who constitute the first and only line of defence against the pandemic, leading to sub-optimal levels of functioning of many healthcare facilities.

Haiyan Qiu and colleagues elaborated little known clinical and epidemiological details of COVID-19 in pediatric population [1]. To help pediatricians clinically screen the patients of COVID-19 and comfortably deal with patient families with unlikely coronavirus infection, a scoring system called "Outbreak of Respiratory Tract Infection Score" or ORTIS System has been devised (Table 1). ORTIS was conceptualized based on expert opinion and review of literature of past outbreaks of viral infections in children with predominant respiratory system involvement [1-5]. The primary purpose of the scale is to confidently rule out the chances of CoVID-19 infection.

The scale was tested by screening 93 consecutive children in the outpatient department of a tertiary care pediatric hospital in North India, between 14 March and 25 March, 2020 (Figure 1). No risk $(24,25.8 \%)$, Low risk (31, 33.3\%), Medium risk $(22,23.6 \%)$ and High risk $(16,17.2 \%)$ children were screened using ORTIS System. Hospital administrative staff, nursing staff and pediatric residents reported a higher degree of comfort and confidence when patients were labelled as No or Low risk. Most (14/22) medium risk patients were given telephonic instructions regarding symptomatic treatment. 8 out of 22 medium risk patient were called for examination and only 2 of the 22 patients required hospital admission. Not all High risk patients were referred to COVID-19 facility, but all of them were asked to exercise extreme caution and were only given telephonic consultations. All 55 "No and Low risk" cases recovered clinically, they were found to be asymptomatic 7 days after consultation. Based on clinical judgement, all these cases were considered true negatives and not asymptomatic carriers. Hence, ORTIS system showed a 100\% Negative Predictive Value.

ORTIS has been designed for implementation in ongoing and any future viral outbreaks with respiratory failure or pneumonia 
as possible complications. The ORTIS System can be performed telephonically which is critical in bifurcating the suspected patients towards COVID-19 dedicated hospitals during the early stages of clinical presentation. This step is crucial in reducing the risk of nosocomial transmission, infection transmission to the community and to the healthcare workers. "No risk" children are typically patients with straightforward diagnosis such as UTI or Neonatal Septicemia. "Low risk" children can be assumed to have an unlikely risk of COVID-19 infection, "Medium risk" children should be carefully evaluated and a follow up evaluation is a must. "High risk" cases should be urgently referred to dedicated centres for outbreak disease. The pilot study has important limitations such as low sample size and study participants not tested for SARS-CoV-2 infection

Table 1: Outbreak of Respiratory Tract Infection Scale (ORTIS System).

SN

7

8

11

12

13

14

15

16

17

18

19

20

\begin{tabular}{|c|c|c|}
\hline & Trauma & 0 \\
\hline 0 & Interpretation \\
$1-2$ & No Risk \\
$3-9$ & Low Risk \\
10 or More & Medium Risk \\
\hline
\end{tabular}

History of contact with positive CoVID-19 case

or a suspected CoVID-19 case

or from localities where CoVID-19 cases have been documented

History of travel out of city / town / village

Radiological finding on Chest X-Ray suggesting Pneumonia

Loss of Taste or Loss of Smell or Both

Breathlessness / SpO2 < 95\%

Fast Breathing / Tachypnea in absence of history of wheezing or asthma

Fever

Dry Cough

Throat congestion

Cough with sputum or Coryza or Both

Headache or Myalgia or Both

Loose stools / Vomiting / Pain Abdomen / Nausea

Unexplained Leucopenia or Thrombocytopenia

Any urinary Symptoms

Epistaxis

Night time and Early morning Coughing and History of Asthma / Recurrent wheezer Neonate

(mother not CoVID-19 positive, no History of fever and cough)

Febrile Seizures / Neck Rigidity and Fever and Vomiting

Follow up visit for chronic condition such as Diabetes, Nephrotic
Syndrome, Seizure Disorder, etc. and planned Immunization visits

10

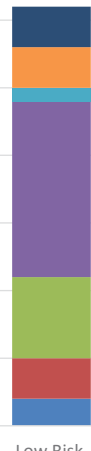

No Risk

- UTI

- Clinical Septicemia (CRP > $40 \mathrm{mg} / \mathrm{dL}$ )

- CNS Infection
- Non COVID-19 Respiratory Tract Infection

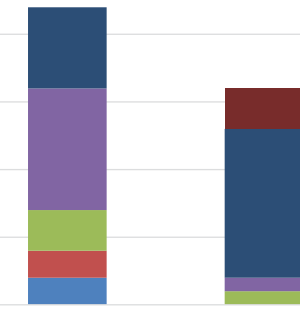

High Risk
- Viral Associated Pyrexia

nEnteric Fever

- Possible COVID-19 risk zones.

by PCR analysis for microbiological confirmation. Although interobserver variation was not assessed, the objective and history based construct of scoring minimizes chances of any variations.

\section{Author's contribution}

VS was responsible for conception of idea, literature review, preparation of manuscript and building figures and tables.

\section{References}

1. Qiu H, Wu J, Hong L, Luo Y, Song Q, et al. (2020) Clinical and epidemiological features of 36 children with coronavirus disease 2019 (COVID-19) in Zhejiang, China: an observational cohort study. Lancet Infect Dis. Link: https://bit.ly/3atkNV7

2. Dong $Y$, Mo X, Hu Y, Qi X, Jiang F, et al. (2020) Epidemiological characteristics of 2143 pediatric patients with 2019 coronavirus disease in China. Pediatrics. Link: https://bit.ly/2VNU3t8

3. , Englund JA, Bradford MC, Qin X, Boeckh M, et al. (2019) Characteristics and outcomes of coronavirus infection in children: the role of viral factors and an immunocompromised state. J Pediatric Infect Dis Soc 8: 21-28. Link: https://bit.ly/3eCkDhm

4. Stockman LJ, Massoudi MS, Helfand R, Erdman D, Siwek AM, et al. (2007) Severe acute respiratory syndrome in children. Pediatr Infect Dis J 26: 68-74. Link: https://bit.ly/2XOdnc8

5. Memish ZA, Perlman S, Kerkhove MDV, Zumla A (2020) Middle East respiratory syndrome. Lancet 395: 1063-1077. Link: https://bit.ly/2yoiF3r

Copyright: (c) 2020 Shanker V. This is an open-access article distributed under the terms of the Creative Commons Attribution License, which permits unrestricted use, distribution, and reproduction in any medium, provided the original author and source are credited. 